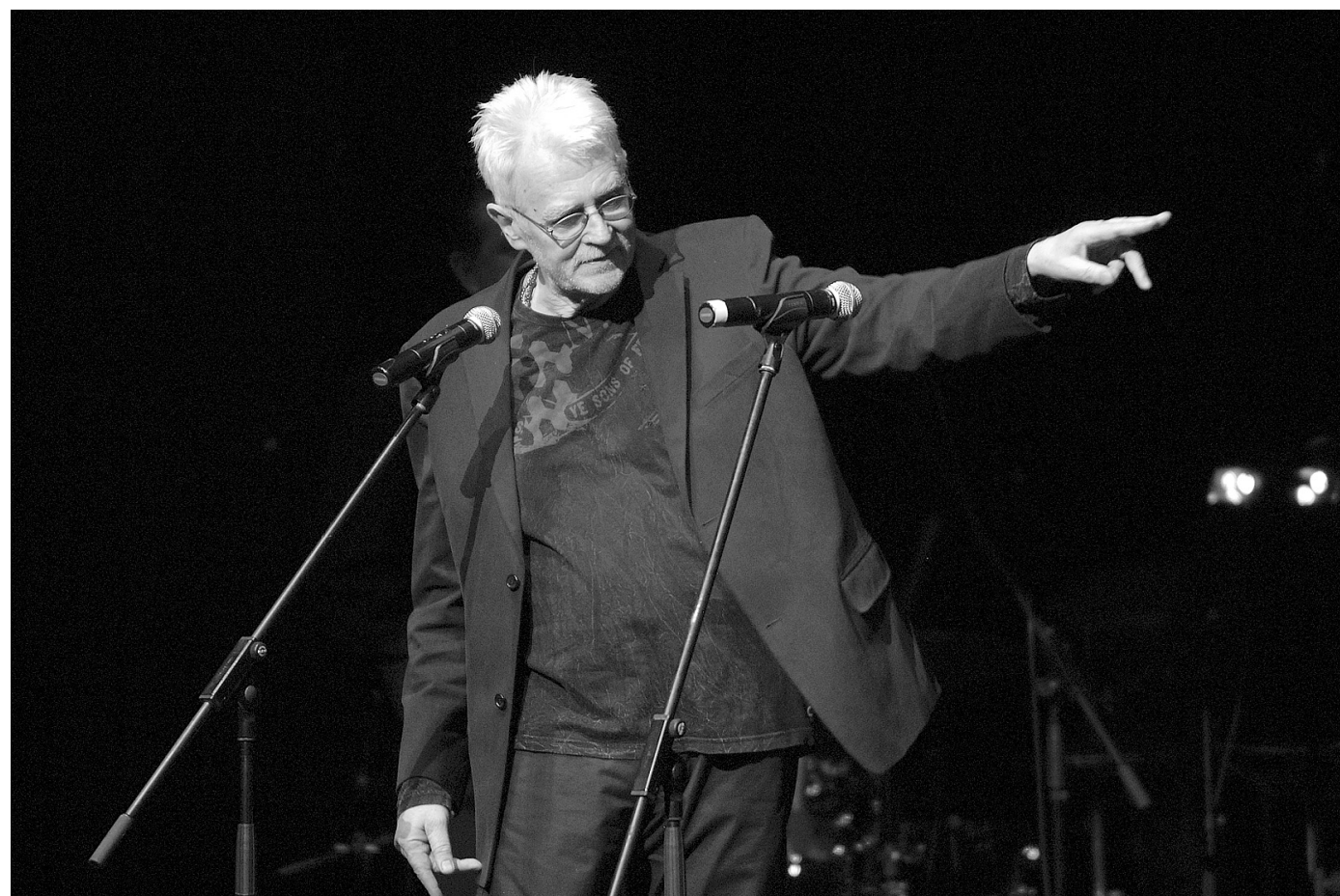

\title{
Prémio Europa para o Teatro 2009 Alguns apontamentos críticos
}

\author{
Paulo Eduardo Carvalho
}

0 Prémio Europa para o Teatro teve, este ano, a sua $13 .^{\text {a }}$ edição na cidade de Wroclaw, na Polónia, entre os dias 31 de Março e 5 de Abril. Para lá de a principal distinção ter sido atribuída ao encenador polaco Krystian Lupa, a escolha de Wroclaw resultou do facto de esta ter sido a cidade para a qual, em 1965, Jerzy Grotowski deslocou o seu "laboratório" e onde estreou o mítico espectáculo O Príncipe Constante, com o actor Ryszard Cieślak no papel do protagonista. 2009 foi, aliás, declarado o "Ano Grotowski" pela UNESCO, facto que plenamente justifica a cooperação do Instituto Grotowski nesta edição do Prémio Europa e a realização de um colóquio, promovido pela Associação Internacional de Críticos de Teatro (AICT) subordinado ao tema "A representação antes e depois de Grotowski". Para além do patrocínio e apoio da União Europeia e do Parlamento Europeu, esta edição do Prémio Europa contou ainda com o apoio do Municipio de Wroclaw e do Ministério da Cultura polaco, tendo envolvido, como habitualmente, a colaboração de diversas outras entidades, como a União dos Teatros da Europa, a AICT, o Instituto Internacional do Teatro do Mediterrâneo, o Instituto Internacional do Teatro e a Associação Europeia de Festivais.

Criado para promover o conhecimento do teatro na Europa, através do desenvolvimento das relações culturais e do enriquecimento de uma consciência colectiva, ao longo dos seus 22 anos de existência e das suas 12 edições, o Prémio Europa para o Teatro já distinguiu com o seu mais alto galardão criadores como Ariane Mnouchkine e o Théâtre du Soleil, Peter Brook, Giorgio Strehler, Heiner
Müller, Robert Wilson, Luca Ronconi, Pina Bausch, Lev Dodin, Michel Piccoli, Harold Pinter, Robert Lepage, Peter Zadek e Patrice Chéreau. Com apenas 10 edições, o Prémio Europa para as Novas Realidades Teatrais tem sido mais abrangente, embora também, por vezes, mais confusamente prolixo, distinguindo realidades muito diversas, algumas das quais, nestas duas últimas décadas, o espectador português foi tendo a oportunidade de conhecer: Anatoli Vassiliev, Giorgio Barberio Corsetti, Els Comediants,

Eimuntas Nekrosius, Théâtre de Complicité, Carte Blanche - Compagnia della Fortezza, Christoph Marthaler, Royal Court Theatre, Theatergroep Hollandia, Thomas Ostermeier, Societas Rafaello Sanzio, Heiner Goebbels, Alain Platel, Oskaras Korsunovas, Josef Nadj, Alvis Hermanis, Biljana Srbljanović, Rimini Protokoll, Sasha Waltz e Krysztof Warlikowski. Nesta 13.a edição, um júri - assaz "masculino", diga-se - constituído por Franco Quadri, Renzo Tian, Georges Banu, Manfred Beilharz, Jean Claude Berutti, Alexandru Darie, Marina Davydova, lan Herbert, José Monleon, Milos Mistrik e Arthur Sonen distinguiu com o Prémio Europa para o Teatro, como atrás já se adiantou, o encenador Krystian Lupa, tendo o prémio para as Novas Realidades Teatrais sido distribuído por cinco criadores bem distintos: o belga Guy Cassiers, o italiano Pippo Delbono, 0 argentino-espanhol Rodrigo Garcia, o húngaro Árpád Schilling e o francês François Tanguy e o seu Théâtre du Radeau.

Uma das dimensões mais apreciáveis do Prémio Europa vem sendo o esforço de efectiva celebração dos seus premiados, seja através da apresentação de espectáculos, 

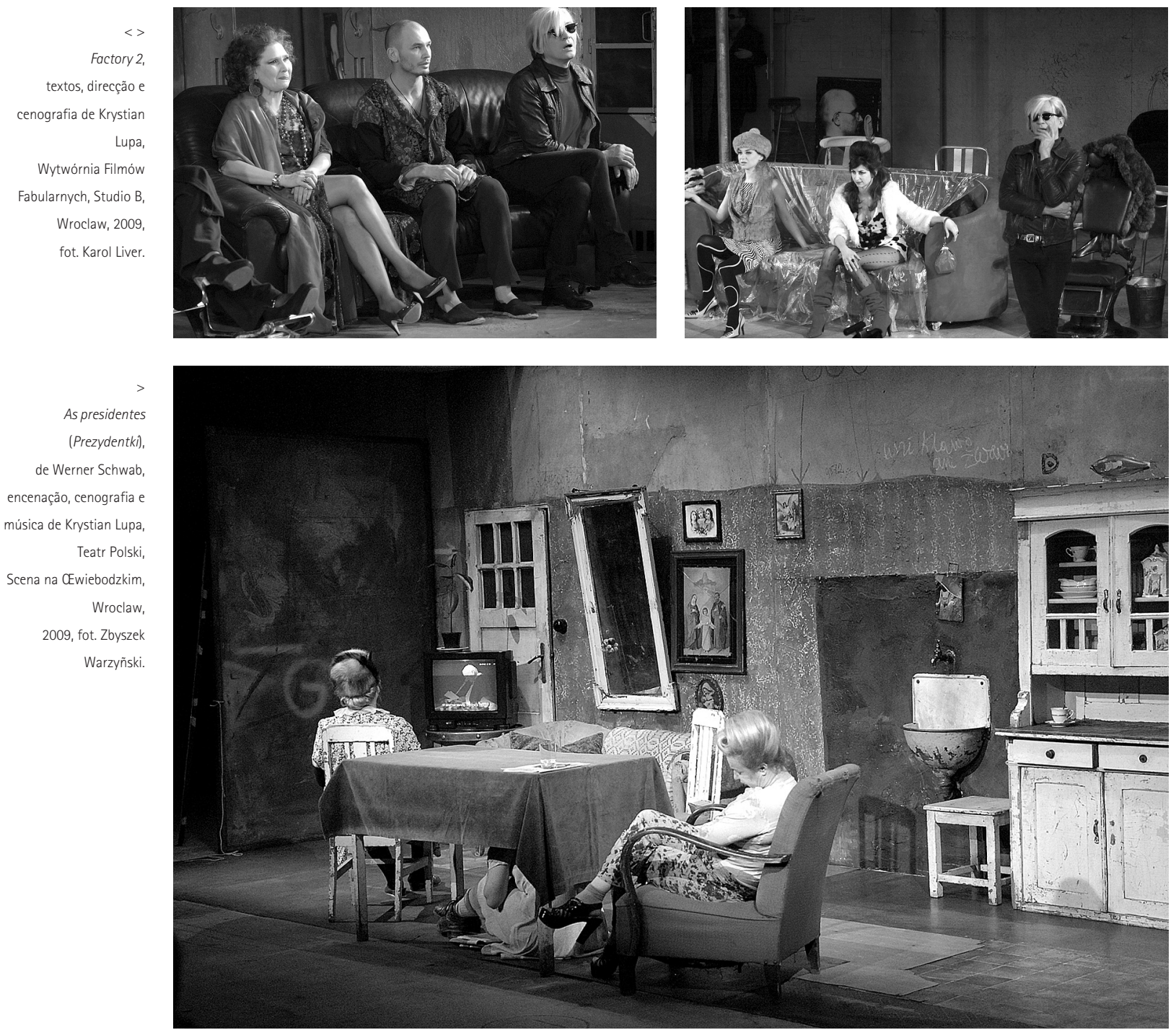

de algum modo, representativos da distinção que thes é concedida, seja através da organização de encontros, colóquios e outras formas de debate público das carreiras respectivas. 0 teatro é, contudo, uma arte que contrariamente, por exemplo, ao cinema ou às artes visuais - oferece particulares resistências a uma qualquer tentativa mais efectiva ou alargada de revisitação: para lá dos estudos já publicados ou dos registos vídeo que possam existir, não é fácil - pode dizer-se mesmo que é impossive - recuperar uma amostra significativa do que possa ter sido o percurso artístico de um criador cénico que já leve mais de dez, vinte, trinta ou quarenta anos de actividade. 0 programa final que é oferecido aos participantes destas edições do Prémio Europa é, assim, o resultado não tanto de escolhas deliberadas, mas de contingências de programação, isto é, da disponibilidade de determinados espectáculos e da sua possibilidade de apresentação num determinado lugar, durante o período de uma semana. E muito embora os diversos especialistas reunidos nos espaços de discussão se esforcem por oferecer uma visão mais alargada das obras dos diferentes criadores, por vezes até com o recurso a imagens, fotográficas ou em vídeo, acabam sempre por ser os espectáculos apresentados os veículos mais imediatos e mais marcantes para aceder ao universo dos premiados.
Forçados a uma convivência próxima, durante 0 período de quase uma semana, os muitos participantes destas edições do Prémio Europa - entre jornalistas, críticos, programadores, e até mesmo criadores - vão tendo a oportunidade, mesmo quando não voluntária, de trocar opiniões sobre os espectáculos apresentados, manifestando entendimentos e sensibilidades tão diversas como diversa se revela, efectivamente, a paisagem teatral europeia neste início de milénio, e, desse modo, validando ou interrogando as escolhas do júri. Uma tal diversidade de reacções - perceptível, desde logo, através do comportamento dos espectadores durante os espectáculos e no momento final dos aplausos - leva-nos a interrogar o alcance ou a consequência do próprio exercício crítico relativizando qualquer tentativa de recuperação da nossa experiência individual. É com esse tipo de consciência, de forma alguma inibidora da mais tenaz das convicções pessoais, que aqui se registam alguns apontamentos críticos em torno dos espectáculos apresentados em Wroclaw e dos criadores distinguidos.

Do principal premiado, Krystian Lupa - conhecido sobretudo pelos seus trabalhos de adaptação cénica de grandes romances do cânone ocidental, como os de Dostoievski, Musil ou Bernhardt, mas desconhecido dos palcos portugueses - foi possivel ver três experiências 

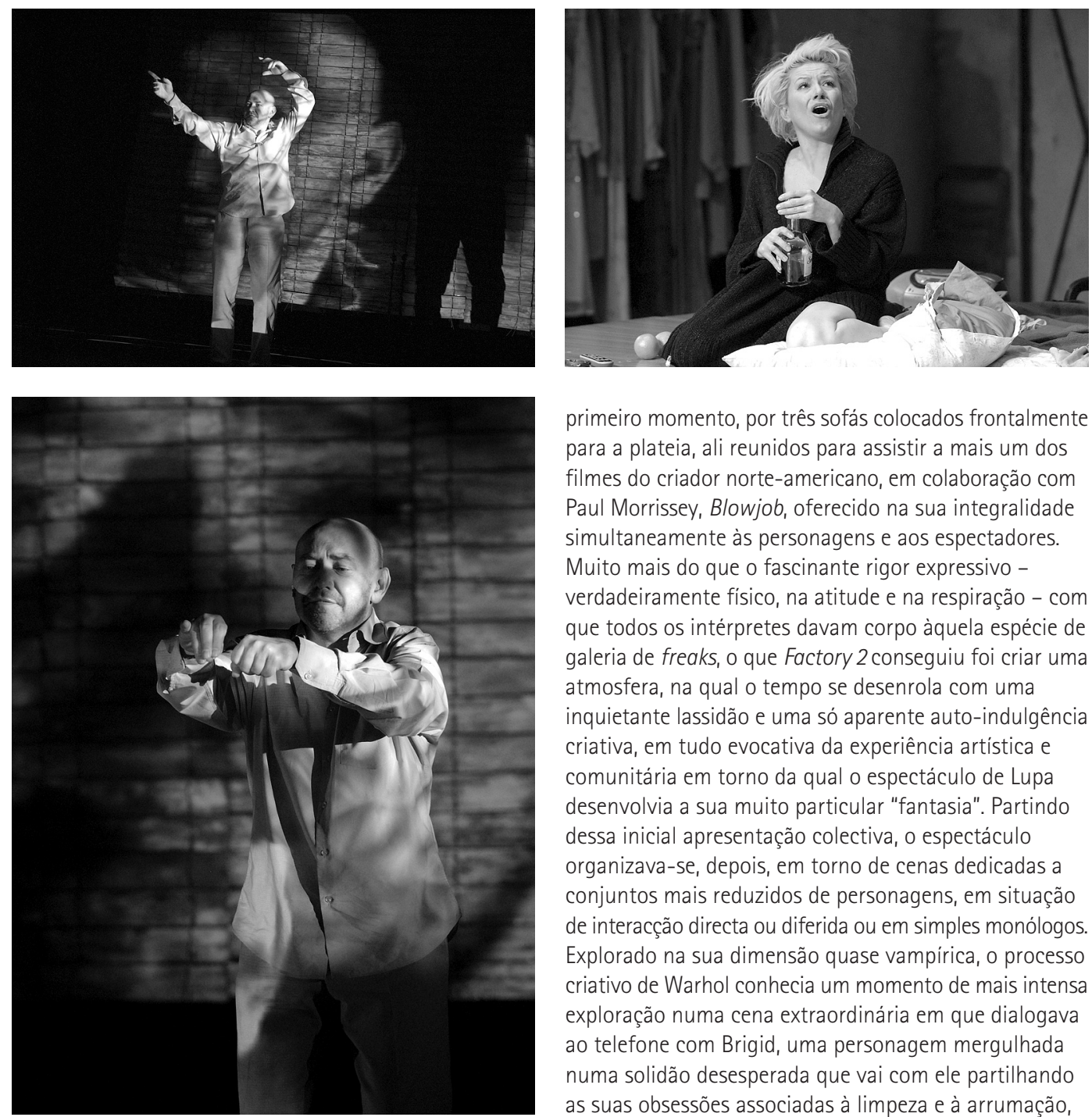

assaz distintas: Factory 2, "uma fantasia colectiva inspirada pela obra de Andy Warhol"; a sua encenação de As presidentes, de Werner Schwab (um texto revelado em Portugal pelo Teatro Aberto, em 1996); e um ensaio da primeira parte daquilo que virá a ser um novo espectáculo, um Tríptico dedicado às figuras de Marilyn Monroe, Simone Weil e Gurdjieff. Se As presidentes permitiu confirmar um trabalho rigoroso na direcção de actores - subtil na exploração quase expressionista de uma espécie difícil de hiperrealismo -, o ensaio da primeira parte do referido tríptico, dedicado à figura de Marilyn Monroe, teve talvez como única utilidade vislumbrar o tipo de labor desenvolvido pelo criador na montagem de espectáculos como Factory 2, uma longa jornada cénica, com cerca de 7 horas de duração, com textos, encenação e cenografia do próprio Krystian Lupa.

Para lá do eventual prazer de vermos recriadas e animadas muitas das personagens desse quase mítico "bestiário" que efectivamente habitou a celebrada Factory de Warhol e que podemos só conhecer através de fotografias, o espectáculo do encenador polaco conseguiu proporcionar a experiência rara de partilha de um tempo e de um espaço, através de uma singular gestão, sobretudo, dos recursos expressivos dos cerca de 19 intérpretes do espectáculo. Instaladas num vasto espaço integralmente pintado de prateado, as personagens distribuiam-se, num primeiro momento, por três sofás colocados frontalmente para a plateia, ali reunidos para assistir a mais um dos filmes do criador norte-americano, em colaboração com Paul Morrissey, Blowjob, oferecido na sua integralidade simultaneamente às personagens e aos espectadores. Muito mais do que o fascinante rigor expressivo que todos os intérpretes davam corpo àquela espécie de galeria de freaks, o que Factory 2 conseguiu foi criar uma atmosfera, na qual o tempo se desenrola com uma inquietante lassidão e uma só aparente auto-indulgência criativa, em tudo evocativa da experiência artística e comunitária em torno da qual o espectáculo de Lupa desenvolvia a sua muito particular "fantasia". Partindo dessa inicial apresentação colectiva, o espectáculo organizava-se, depois, em torno de cenas dedicadas a conjuntos mais reduzidos de personagens, em situação de interacção directa ou diferida ou em simples monólogos. Explorado na sua dimensão quase vampírica, o processo criativo de Warhol conhecia um momento de mais intensa exploração numa cena extraordinária em que dialogava ao telefone com Brigid, uma personagem mergulhada numa solidão desesperada que vai com ele partilhando as suas obsessões associadas à limpeza e à arrumação, enquanto o artista, motivado por uma referência inicial da mesma Brigid a um programa de televisão sobre as execuções por cadeira eléctrica, vai pintando um quadro sobre o tema. Quase beckettiano, na sua dimensão obsessiva com o pormenor, o discurso de Brigid, projectado no ecrã sobre o palco, constituiu uma das sequências mais marcantes de um espectáculo sem dúvida raro, singularmente investido, não obstante a sua reconhecida origem em exercícios de improvisação.

Os espectáculos dos distinguidos pelo Prémio das Novas Realidades Teatrais permitiram confirmar a já referida diversidade de propostas contempladas e de experiências proporcionadas, entre o entusiasmo de novas descobertas, a sobrevivência de algumas perplexidades e a confirmação de desagradáveis decepções. Guy Cassiers, o actual director do Teatro Municipal de Antuérpia, apresentou Vermelho fundo, adaptação do texto homónimo da mãe e a recordação da experiência vivida num campo de concentração japonês durante a Segunda Guerra Mundial. Servido por um intérprete de excepção, Dirk Roofthooft, o espectáculo de Cassiers oferecia-se como uma espécie de poema cénico, de concepção rigorosa e extrema consequência expressiva, particularmente no uso da luz e da projecção de imagens vídeo captadas em directo, projectando o palco para novos espaços do verdadeiramente físico, na atitude e na respiração - com de Jeroen Brouwers, uma espécie de lamento pela morte
Persona Tryptyk, textos, encenação e cenografia de Krystian Lupa, Studio ATM, Wroclaw, 2009 fot. Karol Liver.

Vermelho fundo (Sunken Red), a partir do romance de Jeroen Brouwers, encenação de Guy Cassiers, Teatr Polski, Scena im.J.Grzegorzewskiego, Wroclaw, 2009, fot. Zbyszek Warzyñski. 
História de uma viagem

teatral

(Storia di un viaggio Teatrale),

de Pippo Delbono,

Wroclawski Teatr Lalek,

Wrolfaw, 2009 fot. Karol Liver.

Otempo dos assassinos

[/l tempo degli assassini),

de Pippo Delbono, Teat

Muzyczny Capitol,

Wroclfaw, 2009,

fot. Zbyszek Warzyñsk imaginário, explorando as potencialidades do ecrã na abertura da cena tanto ao infinitamente intimo como ao infinitamente grande, na formulação feliz de Béatrice Picon-Vallin (1998: 27).

Pippo Delbono é um criador que, nos últimos anos tem tido uma presença regular em Portugal, com a apresentação de A raiva, Guerra e 0 silêncio no Centro Cultural de Belém, em 2004, e Exodo, no mesmo CCB, mas este no âmbito do Festival Internacional de Almada, em 2006. Em 2007, foi a vez de 0 tempo dos assassinos, na Fundação de Serralves no Porto, justamente um dos espectáculos apresentados em Wroclaw, juntamente com uma espécie de conferência-performance, História de uma viagem teatral aos lugares por descobrir entre a fúria e o amor, a solidão e o encontro, o constrangimento e a liberdade, e o mais ambicioso Esta escuridão feroz, livremente inspirado no livro homónimo de Harold Brodkey, um relato autobiográfico sobre um destino marcado pela SIDA.

Não obstante a intensidade quase selvagem ou a rude beleza de alguns momentos - comovente a breve sequência de À espera de Godot com Bobò, um dos seus mais icónicos intérpretes, em História de uma viagem..., e fascinante 0 início de Esta escuridão feroz -, há na prática artística de Delbono algo que desperta algumas reservas inquietantes seja no uso abusivo da banda sonora, que por vezes se substitui ao labor mais exigente das linguagens da cena, seja na por demais indulgente construção dos próprios espectáculos, assentes numa dramaturgia de simples sucessão de quadros ou de números. Entre a manifestação mais surpreendente e expressiva de um "teatro pobre" caso do fundador 0 tempo dos assassinos, de 1986 - e a quase barroca acumulação de efeitos, por via da música, das silhuetas e dos contrastes cromáticos dos figurinos, do recorte físico dos próprios intérpretes - como em Esta escuridão feroz -, este é um teatro, sem dúvida, capaz de produzir os maiores arrebatamentos, mas também de levantar as mais sérias questões sobre as regras do seu funcionamento.

Mais inequivocamente falacioso nos seus pressupostos artísticos e mais desabridamente demagógico nas suas propostas pareceram dois dos trabalhos de Rodrigo Garcia apresentados em Wroclaw, Acidentes (matar para comer) e Lançai as minhas cinzas sobre Mickey - foi ainda apresentado 0 cão, uma performance realizada com actores polacos. 0 criador argentino, mas fixado em Espanha, tem sido uma presença regular no Citemor, o Festival de Teatro de Montemor-o-Velho, com a sua companhia, La Carniceria Teatro, tendo apresentado, entre 2002 e 2006, diversos espectáculos como A história de Ronald, o palhaço do McDonals's, Comprei uma pá na Ikea para cavar a minha
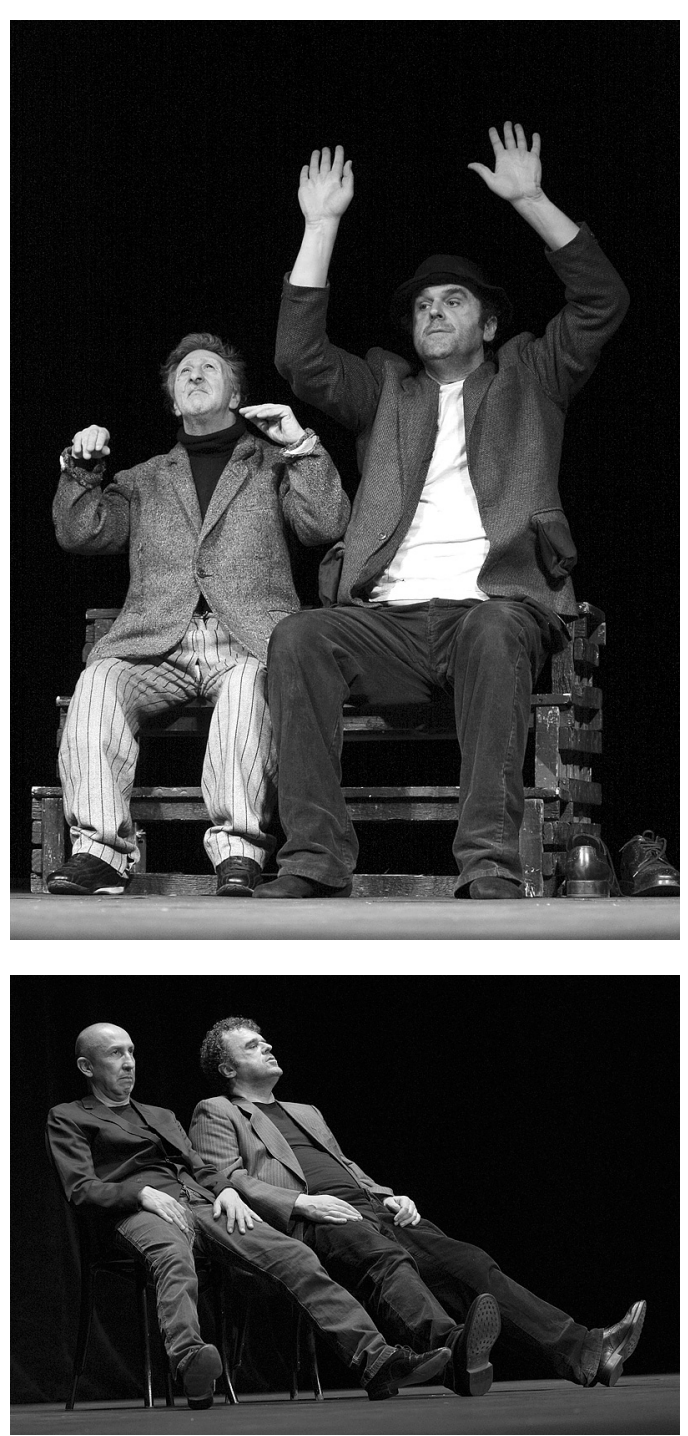

sepultura, o já referido Acidentes e Aproximação à ideia de desconfiança, a que se acrescenta ainda Levantem a cabeça do chão, cabrões!, um trabalho apresentado no Porto, no Rivoli Teatro Municipal, em 2005, no âmbito de uma edição do Projecto Thierry Salmon. Intensamente "performativo", no sentido em que está mais interessado em explorar breves acontecimentos cénicos do que em construir qualquer tipo de ficção dramatúrgica, este é um teatro que parece cair na absurda armadilha de se desenvolver socorrendo-se das próprias realidades que, aparentemente, se propõe combater ou, mais ingenuamente, denunciar. 0 próprio "adormecimento" ou insensibilização induzida pelos meios de comunicação na nossa sociedade capitalista globalizada parece acabar por encontrar paralelo no zapping aparentemente irrelevante de imagens com que Garcia constrói os seus espectáculos, um coktail de situações completamente desprovidas de uma qualquer interrogação expressiva - acreditando na sua simples capacidade de chocar - ou de investimento imaginativo. Um equívoco que parece ter encontrado um inesperado reconhecimento institucional.

Num quase extremo oposto parecem situar-se os espectáculos que François Tanguy vem construindo com o seu Théâtre du Radeau, de que Lisboa pôde ver um exemplo, 0 canto do bode, em 1992, no âmbito da segunda 

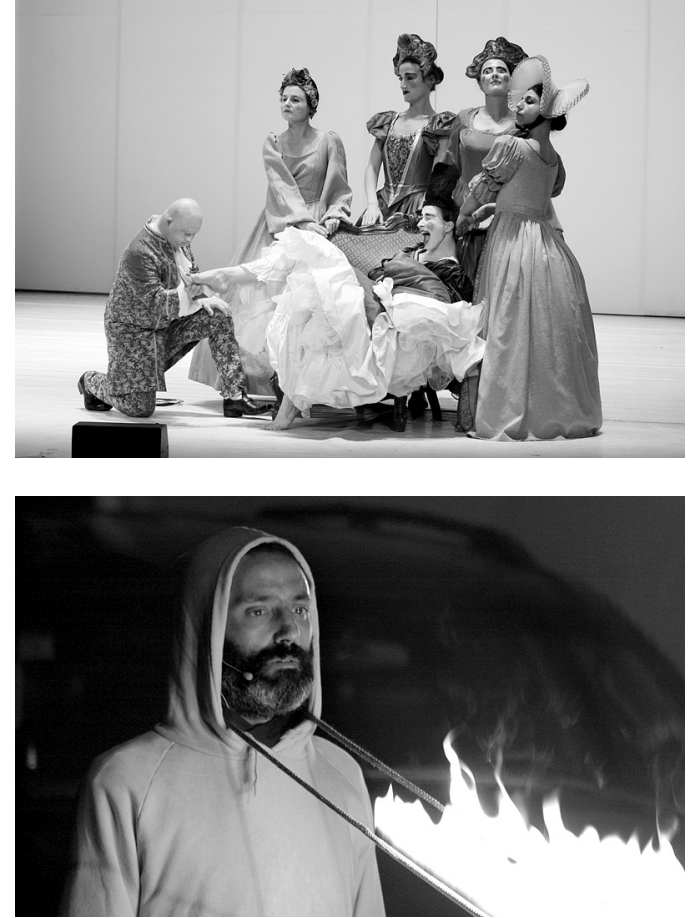

edição do efémero Festival Internacional de Teatro, e o Porto, mais recentemente, um outro, As cantatas, durante a alargada programação internacional do Teatro Nacional S. João para a Capital Europeia da Cultura em 2001. Era justamente a propósito desse já antigo Canto do bode que o nosso colega Jean-Pierre Han escrevia, em 1991, que "Os espectáculos de François Tanguy e do Théâtre du Radeau possuem essa virtude essencial, e rara, de tornarem impossivel qualquer discurso crítico" (2008: 73): há, na realidade, nestes espectáculos uma espécie rara de arte da metamorfose - o espaço cénico está em constante mutação, devido à incessante deslocação, operada pelos intérpretes, de telas, tábuas e outros materiais vários -, que se abre a instantes imagéticos de uma extraordinária fulgurância poética, que escapam ao esforço descritivo. 0 espectáculo apresentado em Wroclaw voltava a convocar um termo musical, Ricercar, para configurar uma experiência hipnótica, muito devedora da liberdade experimental do primeiro modernismo, assente numa montagem de textos de diversos autores, nas mais diversas línguas - textos que parecem valer mais pela sua materialidade significante do que por aquilo que nos possam comunicar, à imagem da laboriosa banda sonora, capaz de imprimir a todo o espectáculo uma espécie de propulsão frenética e surrealizante. Sobrevive, contudo, uma dimensão quase solipsista que em muito compromete uma comunicabilidade que se poderia desejar mais generosa.

Árpád Schilling - que apresentou uma inesquecivel Gaivota em Lisboa, na Culturgest, em 2005 - não teve a possibilidade de levar a Wroclaw nenhum espectáculo, tendo-se limitado a realizar, no final do colóquio que the foi dedicado, uma espécie de exposição ilustrada com breves sequências vídeo do trabalho mais recente que vem desenvolvendo com a sua renovada companhia, o Teatro Krétakör, sob o título de Apologia de um escapologista: Um trabalho em curso do Krétakör. 0 criador húngaro parece actualmente mais apostado em alargar o seu papel social, ultrapassando os enquadramentos tradicionais do

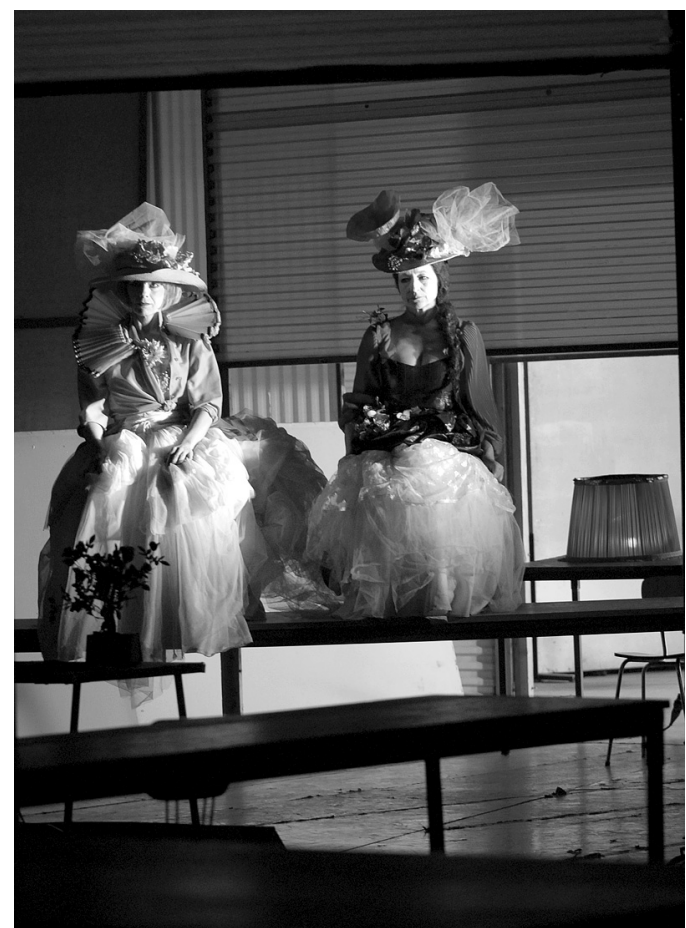

Esta escuridão feroz (Questo buio feroce), de Pippo Delbono, Teatr Muzyczny Capitol, Wroclaw, 2009, fot. Rafal Nowak.

Lançai as minhas cinzas sobre Mickey, texto e direcção de Rodrigo Garcia, Wytwórnia Filmów Fabularnych, Wroclaw, 2009, fot. Karol Liver.

teatro, numa demanda de espaços mais comunitários para o exercício de uma intervenção criativa que se apresenta quase como uma espécie de "terapia cívica". Ficou, assim o vislumbre de uma nova experiência, nas fronteiras daquilo a que ainda poderemos chamar criação teatral, mas profundamente conduzida por um desejo de reinvenção das modalidades possiveis de intervenção na nossa dinâmica social comum.

Paralelamente ao programa do Prémio Europa, foi ainda possivel ver espectáculos de companhias locais, como o Teatr Zar - uma estrutura de criação teatral cujas principais fontes de inspiração são as diferentes tradições musicais ocidentais e orientais - ou o Teatr Piesn Kozla, de que se falou no último número da Sinais de cena e que mostrou uma abordagem singular a Macbeth, de

Shakespeare, num espectáculo intensamente físico e também musical, apostado numa quase quimérica pureza expressiva, de algum modo, ainda devedora da prática de Jerzy Grotowski. 0 Instituto que leva o nome do criador polaco, actualmente dirigido por Jaroslaw Fret e instalado no verdadeiro coração da cidade de Wroclaw, apresentou também alguns trabalhos aos espectadores mais curiosos em testemunhar a continuidade de um dos mais radicais e influentes legados teatrais do século XX europeu, quanto mais não fosse pelo desafio lançado, como recorda Peter Brook (2009: 11), pela intensidade, honestidade e precisão do seu trabalho - valores assaz recomendáveis neste turbulento início de século.

\section{Referências bibliográficas}

BR00K, Peter (2009), With Grotowski, Wroclaw, the Grotowski Institute. HAN, Jean-Pierre (2008), Derniers feux: Essais de critiques, Carnières Morlanwelz.

PICON-VALLIN, Béatrice (1998), "Hybridation spatiale, registres de présence", in Les Écrans sur la scène, dir. Béatrice Picon-Vallin, Lausanne, L'Age d'homme, 1998, pp. 9-35.
Ricercar,

encenação, cenografia e desenho de luz de François Tanguy, Théâtre du Radeau, Wytwórnia Filmów Fabularnych, Wroclaw, 2009, fot. Zbyszek Warzyñski. 